\title{
Synthesis of a highly metal-selective rhodamine- based probe and its use for the in vivo monitoring of mercury
}

\author{
Young-Keun Yang, Sung-Kyun Ko, Injae Shin \& Jinsung Tae
}

Department of Chemistry, Yonsei University, Seoul 120-749, Korea. Correspondence should be addressed to J.T. (jstae@yonsei.ac.kr) or I.S. (injae@yonsei.ac.kr).

Published online 5 July; corrected online 9 August 2007 (details online); doi:10.1038/nprot.2007.246

\begin{abstract}
This protocol describes detailed procedures for the preparation of a rhodamine-based mercury probe and for its applications to the detection of mercury in cells and vertebrate organisms. The mercury probe 1 , which is prepared in two steps from rhodamine $6 \mathrm{G}$, responds rapidly to $\mathrm{Hg}^{2+}$ in aqueous solutions with a $1: 1$ stoichiometry. 0 wing to the fact that the probe reacts with $\mathrm{Hg}^{2+}$ in an irreversible manner, it has advantages over other reversible mercury probes in in vivo assays with respect to both sensitivity and selectivity. In addition, fluorescent imaging assays of $\mathrm{Hg}^{2+}$ in live cells and zebrafish by using this mercury probe are detailed in this protocol. The approximate time frame for the preparation of the probe is $24 \mathrm{~h}$ and for its use in imaging assays is $1.5 \mathrm{~h}$.
\end{abstract}

\section{INTRODUCTION}

Mercury, a highly toxic metal, can easily pass through biological membranes ${ }^{1}$. Mercury absorbed in human bodies causes serious damage to tissues and organs ${ }^{2}$. Long-term exposure to high levels of mercury results in deterioration of the brain and kidneys, while short-term exposure to high levels of this metal leads to lung damage, nausea, vomiting and diarrhea. Despite the serious toxic effects on biological systems, efficient and sensitive in vivo monitoring methods for mercury have not been fully developed ${ }^{3}$. Because of their high sensitivity, simplicity and reproducibility, fluorescent chemosensor techniques ${ }^{4-8}$ have been extensively employed for the detection of biologically important metal ions. However, most of the known mercury fluorescent chemosensors ${ }^{9-11}$ do not meet the selectivity and sensitivity requirements for the in vivo, aqueous solution imaging assays.

The recently uncovered, rhodamine-based fluorescent probe $\mathbf{1}$ (Fig. 1) has been found to be ideally suited for the in vivo monitoring of mercury ions because of its high sensitivity and selectivity. This protocol describes the method for preparation of the fluorescent probe $\mathbf{1}$ (Fig. 1) ${ }^{12}$, and its application to monitoring of $\mathrm{Hg}^{2+}$ in living cells and zebrafish as a model of vertebrate organisms ${ }^{13}$. Unlike other probes, which operate by reversible binding to metal ions, the response of this probe to $\mathrm{Hg}^{2+}$ is associated with an irreversible chemical reaction ${ }^{14}$. In general, the signal intensities of reversible probes depend on the position of the binding equilibrium, which is sensitive to the environmental conditions, such as $\mathrm{pH}$ and the presence of other chelating molecules. However, those of irreversible probes are proportional to the extent of the chemical conversions not to the equilibrium

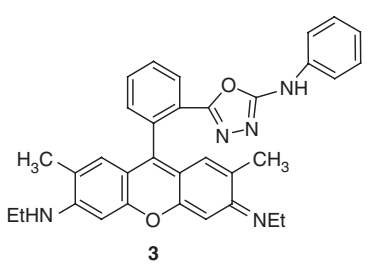

Figure 2 | Structure of compound $\mathbf{3}$ produced by the reaction of mercury probe 1 and $\mathrm{Hg}^{2+}$.

positions, and therefore are less sensitive to the environmental conditions compared with the reversible cases. As a consequence, irreversible probes are more suitable for in vivo assays than reversible probes with respect to their high selectivity and sensitivity. Probe 1, prepared from rhodamine $6 \mathrm{G}$ in high yield by a two-step procedure ${ }^{15}$, has several advantageous features. These include the fact that non-fluorescent 1 reacts irreversibly with $\mathrm{Hg}^{2+}$ in a $1: 1$ stoichiometric fashion to produce the $1,3,4-$ oxadiazole 3 (Fig. 2), a substance that is strongly fluorescent at long wavelengths (emission at $557 \mathrm{~nm}$ ) where background autofluorescence in cells is minimal. In addition, the probe shows a high selectivity to $\mathrm{Hg}^{2+}$ over other biologically relevant metal ions (see Table $\mathbf{1}$ for the selectivity profile of $\mathbf{1}$ ) and a high sensitivity for $\mathrm{Hg}^{2+}$ in aqueous solutions ( $1 \mathrm{ppb}$ of $\mathrm{Hg}^{2+}$ in aqueous solutions can be detected by this probe). Moreover, in addition to the above-mentioned features, its high cell permeability makes it possible to employ 1 to detect $\mathrm{Hg}^{2+}$ in living cells and, in particular, vertebrate organisms. Fluorescence images of the cells and zebrafish that are treated with $\mathrm{Hg}^{2+}$ and then incubated with the mercury probe $\mathbf{1}$ allow rapid in vivo assays of $\mathrm{Hg}^{2+}$. In vivo imaging of $\mathrm{Hg}^{2+}$ by using fluorescent probe technique can provide important information about the site-specific accumulation and real-time monitoring of $\mathrm{Hg}^{2+}$ uptake.

Figure 1 | Synthesis of mercury probe 1.

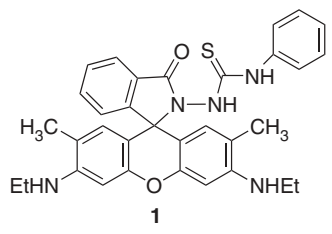

2

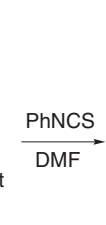


TABLE 1 | Fluorescence response of 1 to various metal ions.

\begin{tabular}{|c|c|c|c|c|c|c|c|c|c|c|c|c|c|c|}
\hline & $\mathrm{Hg}^{2+}$ & $\mathrm{Pb}^{2+}$ & $\mathrm{Zn}^{2+}$ & $\mathrm{Ca}^{2+}$ & $\mathrm{Cd}^{2+}$ & $\mathrm{Cr}^{2+}$ & $\mathrm{Mg}^{2+}$ & $\mathrm{Fe}^{2+}$ & $\mathrm{Ag}^{+}$ & $\mathrm{Cu}^{2+}$ & $\mathrm{Mn}^{2+}$ & $\mathrm{Ni}^{2+}$ & $\mathrm{Ba}^{2+}$ & $\mathrm{Co}^{2+}$ \\
\hline$F / F_{0}$ in solutions ${ }^{a}$ & 25 & 1.1 & 1.8 & 1.4 & 1.1 & 1.5 & 1.1 & 1.4 & 2.8 & 1.5 & 1.1 & 1.1 & 1.0 & 1.1 \\
\hline$F / F_{0}$ in cells $s^{b}$ & 35 & 1.2 & 1.2 & 1.0 & 1.1 & 1.1 & 1.2 & 1.2 & $-^{c}$ & - & - & - & - & - \\
\hline
\end{tabular}

$F_{0}=$ fluorescence intensity of $\mathbf{1}$ in the absence of metal ions, $F=$ fluorescence intensity of $\mathbf{1}$ in the presence of a metal ion at $557 \mathrm{~nm}$ (excitation at $\left.500 \mathrm{~nm}\right)$. ${ }^{\mathrm{a}} \mathrm{Conditions:} \mathbf{1}(1 \mu \mathrm{M})+1$ equivalent of metal ions in water-methanol $(80 / 20 \mathrm{vol} / \mathrm{vol})$. b ${ }^{b}$ Conditions: $1(10 \mu \mathrm{M})+$ metal ions $(200 \mu \mathrm{M})$ in $\mathrm{C} 2 \mathrm{C} 12$ cells in PBS buffer. ${ }^{\mathrm{C}}$ In vivo experiments are not conducted.

\section{MATERIALS}

REAGENTS

- Rhodamine 6G (Sigma-Aldrich, cat. no. R4127)

- Hydrazine monohydrate (Sigma-Aldrich, cat. no. 207942) ! CAUTION Toxic and dangerous for the environment (see material safety data sheet at http:// www.sigmaaldrich.com/catalog/search/ProductDetail/SIAL/207942).

- Phenyl isothiocyanate (Sigma-Aldrich, cat. no. 139742) ! CAUTION Highly toxic, combustible, flammable and harmful if swallowed (see material safety data sheet at http://www.sigmaaldrich.com/catalog/search/ProductDetail/ ALDRICH/139742).

- Mercury(II) chloride (Sigma-Aldrich, cat. no. 203777) I CAUTION Highly toxic and dangerous for the environment (see material safety data sheet at http:// www.sigmaaldrich.com/catalog/search/ProductDetail/ALDRICH/203777).

- Sodium hydroxide (Samchun Chemicals, cat. no. 122401)

- HPLC grade methanol (Burdick \& Jackson, cat. no. AH230)

- Dimethyl sulfoxide (DMSO) (Sigma-Aldrich, cat. no. 276855)

- Anhydrous N,N-dimethylformamide (Sigma-Aldrich, cat. no. 227056)

- HPLC grade dichloromethane (Burdick \& Jackson, cat. no. AH300)

- HPLC grade ethyl acetate (Burdick \& Jackson, cat. no. AS100)

- HPLC grade hexanes (Burdick \& Jackson, cat. no. GC 217)

- Anhydrous magnesium sulfate (Duksan Chemicals, cat. no. A402131)

- DMEM (Invitrogen, cat. no. 11995)

- FBS (Sigma-Aldrich, cat. no. 12103C)

- Trypsin-EDTA solution (Sigma-Aldrich, cat. no. T4174)

$\cdot 100 \times$ penicillin/streptomycin (Invitrogen, cat. no. 15140)

- Phosphate-buffered saline, $1 \times$ sterile solution (PBS, pH 7.4) (Amresco, cat. no. K812)

\section{EQUIPMENT}

- Hotplate magnetic stirrer with contact thermometer (Corning)

- Vacuum pump (Hitachi)

- Rotary evaporator (Heidolph)

- Balance (OHAUS)

-Hand-held UV lamp (Vilber Lourmat)

- Rubber septum (Sigma-Aldrich, cat. no. Z553964)

- Disposable glass Pasteur pipettes (Hilgenberg-Gmbh, 150 and $230 \mathrm{~mm}$ )

- Pipette bulbs (Sigma-Aldrich, cat. no. Z136069)

-Pyrex one-necked round-bottomed flasks $(25 \mathrm{ml})$

- Pyrex two-necked round-bottomed flasks $(25 \mathrm{ml})$

- Pyrex separatory funnel

- Pyrex filter funnel

- Filter paper (Fisher, cat. no. 09-801C)

- Pyrex chromatography column (Changyoung)

- Syringe needle (Hamilton, cat. no. 81320/81000)
- Glass syringe (Hamilton)

- Disposable polypropylene syringe (HENKE SASS WOLF GMBH)

- Mercury-free thermometer (Sigma-Aldrich, cat. no. Z561541)

- KBr IR cell (Sigma-Aldrich, cat. no. Z112119)

- Heat gun (Daihan-Scientific, cat. no. BOGHG630)

- Melting point apparatus (Sigma-Aldrich, cat. no. Z289078)

- Teflon-coated magnetic stirring bar (Sigma-Aldrich, cat. no. Z126969)

- NMR tube (Sigma-Aldrich, cat. no. NORS55008)

- NMR (Bruker DRX-250 spectrometer)

- Avatar 360 FT-IR (Nicolet)

- Silica gel 230-400 mesh (Merck, cat. no. TA1363285)

- Silica gel $60 \mathrm{~F}_{254}$ thin-layer chromatography (TLC) plate (Merck, cat. no. OB549444)

- Petri dish (90 mm) (SPL, cat. no. 10090)

- Hemacytometer (Superior, cat. no. HSU-1401)

- Fluorescence microscope (Nicon Eclipse TE2000)

- Charged-coupled device camera (Lumenera, Infinity-2)

- Dissection microscope (Stemi 2000-c, ZAISS)

- Incubator for mammalian cell culture (Sanyo, MCO-5AC)

- Clean bench (Samki-Lab, cat. no. CB2012-840)

- Incubator for zebrafish (Jeio, cat. no. ON-02G)

- Centrifuge (Eppendorf, 5804R)

- Centrifuge tube (15 ml) (Corning, cat. no. 430719)

- Culture flask $\left(25 \mathrm{~cm}^{2}\right)$ (Nunc, cat. no. 136196)

- Multi-well (six-well) plate (Nunc, cat. no. 140675)

-96-well microplate (Nunc, cat. no. 167008)

- Mating box (Fig. 3, fabricated by our group)

- Disposable transfer pipette (Simport, cat. no. P200-72)

REAGENT SETUP

Culture media DMEM supplemented with $10 \% \mathrm{FBS}, 50 \mathrm{U} \mathrm{ml}^{-1}$ of penicillin and $50 \mu \mathrm{g} \mathrm{ml}^{-1}$ of streptomycin.

E3 media $5 \mathrm{mM} \mathrm{NaCl}, 0.17 \mathrm{mM} \mathrm{KCl}, 0.33 \mathrm{mM} \mathrm{CaCl}_{2}, 0.33 \mathrm{mM} \mathrm{MgSO}_{4}$ and $10^{-5} \%$ ( vol/vol) methylene blue.

EQUIPMENT SETUP

When dried round-bottomed flasks are needed for the procedure (see below), store the relevant glassware in the $120{ }^{\circ} \mathrm{C}$ oven for at least $3 \mathrm{~h}$. Before using the dried glassware, allow it to cool to room temperature $\left(25^{\circ} \mathrm{C}\right)$ on the bench top for $5 \mathrm{~min}$. Fluorescence microscope The adduct 3 obtained from reaction of mercury probe 1 and $\mathrm{Hg}^{2+}$ exhibits absorption maximum at $500 \mathrm{~nm}$ and emission maximum at 557 $\mathrm{nm}$. To detect mercury ions in cells and zebrafish using mercury probe $\mathbf{1}$, fluorescence is excited by light from a mercury lamp filtered at wavelength $510-560 \mathrm{~nm}$ and emission is collected at wavelength $590 \mathrm{~nm}$ by a charged-coupled device camera.

\section{PROCEDURE}

Synthesis of 2-(6-ethylamino-3ethylimino-2,7-dimethyl-3H-xanthen9-yl)benzoic acid hydrazide (2)

1) Connect an oven-dried two-necked round-bottomed flask $(25 \mathrm{ml})$

containing a Teflon-coated magnetic stirring bar with a reflux condenser.

Close the openings of the roundbottomed flask and the reflux condenser with rubber septa and fill the flask with argon gas. a

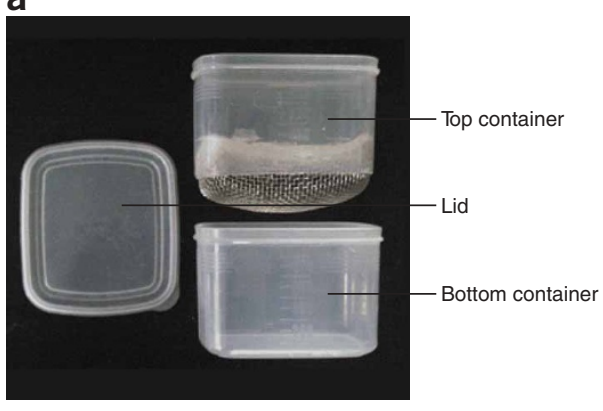

b

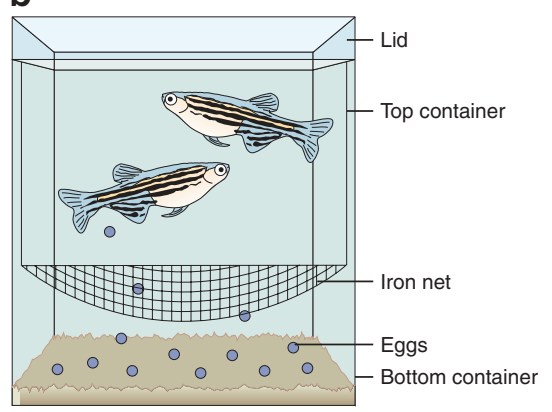

Figure 3 | Figures of a mating box (mesh size: $0.3 \mathrm{~cm}$ ). (a) Real image. (b) Representative diagram. The mating box is composed of a lid, a top container and a bottom container. The bottom of the top container is connected with an iron net. The eggs sink to the bottom container through the iron net and, thus, they cannot be eaten by adults. 
PROTOCOL

2) Add $300 \mathrm{mg}$ rhodamine $6 \mathrm{G}(0.63 \mathrm{mmol}, 1.0$ equiv. $)$ in $2 \mathrm{ml}$ methanol by using a disposable syringe.

3| Add $0.10 \mathrm{ml}$ hydrazine monohydrate $(1.9 \mathrm{mmol}, 3.0$ equiv. $)$ to the flask by using a disposable syringe.

4) Stir the solution at reflux for $6 \mathrm{~h}$ under an argon atmosphere.

5| Cool the reaction mixture to room temperature and add $30 \mathrm{ml}$ ethyl acetate.

6| Transfer the solution into a separatory funnel and dilute it with $50 \mathrm{ml}$ water. Separate the organic layer and extract the aqueous layer with $10 \mathrm{ml}$ ethyl acetate three times (total volume of ethyl acetate: $30 \mathrm{ml}$ ). Wash the combined organic layers with $10 \mathrm{ml}$ of $1 \mathrm{M}$ sodium hydroxide and $5 \mathrm{ml}$ brine ( $\mathrm{NaCl}$-saturated aqueous solution).

7| Dry the organic layer over anhydrous magnesium sulfate $(400 \mathrm{mg})$ for $15 \mathrm{~min}$ with gentle stirring and filter through a fritted glass funnel under an aspirator vacuum. Wash the solids with $25 \mathrm{ml}$ ethyl acetate twice.

8| Concentrate the combined filtrates at $25^{\circ} \mathrm{C}$ by using a rotary evaporator under vacuum $(2 \mathrm{~mm} \mathrm{Hg})$.

PAUSE POINT The crude product can be stored at $4^{\circ} \mathrm{C}$ overnight.

9| Pack a chromatography column $(1.5 \mathrm{~cm}$ i.d. $\times 15 \mathrm{~cm}$ length $)$ with silica gel using hexanes.

10| Load the crude mixture from Step 8 onto the silica bed (approximately $0.5 \mathrm{~cm}$ thick).

11| Elute the product with a 10:2:1 ( $\mathrm{vol} / \mathrm{vol} / \mathrm{vol})$ mixture of hexanes, dichloromethane and methanol.

12| Identify the fractions containing the product by silica gel TLC, developing with a 10:1 mixture of dichloromethane and methanol $\left(R_{\mathrm{f}}=0.51\right.$ for $2, R_{\mathrm{f}}=0.90$ for rhodamine $\left.6 \mathrm{G}\right)$. The product is visualized by UV absorbance at $254 \mathrm{~nm}$.

13 Collect the fractions containing the desired product and evaporate the solvent at $25{ }^{\circ} \mathrm{C}$ by using a rotary evaporator under vacuum $(2 \mathrm{~mm} \mathrm{Hg})$ to give rhodamine hydrazide $2(243 \mathrm{mg}, 0.57 \mathrm{mmol}, 90 \%)$ as a white solid.

PAUSE POINT The product can be stored at $-25^{\circ} \mathrm{C}$ for several weeks.

Synthesis of 2-(6-ethylamino-3-ethylimino-2,7-dimethyl-3H-xanthen-9-yl)benzoic acid phenylthiourea (1)

14| Fit an oven-dried one-necked round-bottomed flask $(25 \mathrm{ml})$ containing a Teflon-coated magnetic stirring bar and close the flask with a septum and fill the flask with argon gas after having briefly set it under vacuum.

15| Add $200 \mathrm{mg}$ rhodamine hydrazide 2 (0.47 mmol, 1.0 equiv.) in $3 \mathrm{ml} \mathrm{N}, N$-dimethylformamide by using a disposable syringe.

16| Add $0.10 \mathrm{ml}$ phenyl isothiocyanate $(0.65 \mathrm{mmol}, 1.4$ equiv. $)$ to the flask by using a disposable syringe.

17| Stir the reaction mixture for $6 \mathrm{~h}$ at room temperature under an argon atmosphere.

18| Dilute the reaction mixture with $30 \mathrm{ml}$ ethyl acetate and transfer the solution to a separatory funnel.

19| Dilute the solution with $30 \mathrm{ml}$ water and separate the organic layer. Extract the aqueous layer with $20 \mathrm{ml}$ ethyl acetate three times and wash the combined organic layers with brine.

20| Dry the organic layer over anhydrous magnesium sulfate $(400 \mathrm{mg})$ for $15 \mathrm{~min}$ with gentle stirring and filter through a fritted glass funnel under aspirator vacuum. Wash the solids with $25 \mathrm{ml}$ ethyl acetate twice.

21 Concentrate the combined filtrates at $25^{\circ} \mathrm{C}$ by using a rotary evaporator under vacuum $(2 \mathrm{~mm} \mathrm{Hg})$.

- PAUSE POINT The crude product can be stored at $4{ }^{\circ} \mathrm{C}$ overnight.

22| Pack a chromatography column $(1.5 \mathrm{~cm}$ i.d. $\times 15 \mathrm{~cm}$ length) with silica gel using hexanes.

23| Load the crude mixture from Step 21 onto the top of the silica gel bed.

24| Elute the products with a 4:1:1 ( $\mathrm{vol} / \mathrm{vol} / \mathrm{vol})$ mixture of hexanes, dichloromethane and ethyl acetate.

25| Identify the fractions containing the desired product by silica gel TLC, developing with a 2:1 mixture of hexanes and ethyl acetate $\left(R_{\mathrm{f}}=0.5\right.$ for $3, R_{\mathrm{f}}=0.10$ for 2$)$. The product is visualized by UV absorbance at $254 \mathrm{~nm}$.

26 Collect the fractions containing the product and evaporate the solvent at $25{ }^{\circ} \mathrm{C}$ using a rotary evaporator under vacuum $(2 \mathrm{~mm} \mathrm{Hg})$ to give the mercury probe $1(238 \mathrm{mg}, 0.42 \mathrm{mmol}, 90 \%)$ as a white solid.

PAUSE POINT This material can be stored at $-25{ }^{\circ} \mathrm{C}$ for several weeks in the dark. 


\section{Detection of mercury ions in mammalian cells}

27| Incubate murine C2C12 cells $\left(2.5 \times 10^{6}\right.$ cells $)$ in a culture flask $\left(25 \mathrm{~cm}^{2}\right)$ containing $8 \mathrm{ml}$ culture media inside an incubator filled with $5 \% \mathrm{CO}_{2}$ for $24 \mathrm{~h}$ at $37^{\circ} \mathrm{C}$.

$\triangle$ CRITICAL STEP Cells should be incubated in an incubator supplemented with $5 \% \mathrm{CO}_{2}$ at $37{ }^{\circ} \mathrm{C}$ to maintain the pH of medium for growth and survival. In general, $5 \% \mathrm{CO}_{2}$ is used with $1.2-2.2 \mathrm{~g} \mathrm{liter}^{-1}$ of sodium bicarbonate in culture medium to buffer the $\mathrm{pH}$ of the medium.

28| Remove culture media from the cell culture and wash the cells with $8 \mathrm{ml}$ culture media.

29| Add $8 \mathrm{ml}$ culture media to cell culture and incubate the cells until they are $60-90 \%$ confluent (usually $24-48 \mathrm{~h}$ ).

30| Remove the culture media from the cell culture and wash the cells with $8 \mathrm{ml}$ sterilized PBS (pH 7.4).

31 Treat the cell culture with $2 \mathrm{ml}$ Trypsin-EDTA solution to detach cells from the surface of the culture flask and incubate the cells until the cell layer is dispersed (usually 5-15 min).

32| Add 6-8 $\mathrm{ml}$ culture media to the cell culture to stop the trypsin reaction, and transfer the cell culture to a $15 \mathrm{ml}$ centrifuge tube.

33| Centrifuge the cells at $180 \mathrm{~g}$ at $25^{\circ} \mathrm{C}$ for 5 min and discard the supernatant.

34| Suspend the cell pellet in culture media and count the number of cells by using a hematometer.

35 Seed $10^{4}$ C2C12 cells per well in a six-well plate.

PAUSE POINT Incubate the cells in $2 \mathrm{ml}$ culture media for $24 \mathrm{~h}$ at $37^{\circ} \mathrm{C}$. Cells are attached to the plate surface during this time.

36| Treat the cells with $2 \mu \mathrm{l}$ of $10 \mathrm{mM}$ mercury chloride (final concentration: $10 \mu \mathrm{M}$ ) dissolved in sterilized PBS (pH 7.4) and incubate for $10 \mathrm{~min}$ at $37^{\circ} \mathrm{C}$.

37| Wash the treated cells three times with $2 \mathrm{~mL}$ PBS to remove the remaining mercury ions. (The exact extent of incorporation of mercury ions into cells is difficult to measure.)

38| Add $2 \mathrm{ml}$ culture media to the cell culture and treat the cell culture with $2 \mu \mathrm{l}$ of $10 \mathrm{mM}$ mercury probe 1 (final concentration: $10 \mu \mathrm{M}$ ) dissolved in DMSO. Incubate for 30 min at $37^{\circ} \mathrm{C}$.

39| Obtain fluorescence images (Fig. 4) by using a Nikon TE2000 fluorescence microscope. There is no need to remove the remaining mercury probe $\mathbf{1}$ from the media as it is not fluorescent.

\section{Detection of mercury ions in zebrafish}

40| Transfer a pair of adult zebrafish ( 3 months old) into a water-filled mating box (Fig. 3 ) by using a small net and cover the box with a lid to prevent the fish from jumping out. Be careful not to injure the fish during the transfer process. Note that the adult zebrafish is purchased from a local pet store. See ref. 16 for detailed procedures for zebrafish maintenance and breeding.

$\triangle$ CRITICAL STEP Zebrafish should be raised at $25-28{ }^{\circ} \mathrm{C}$ (optimal temperature: $28{ }^{\circ} \mathrm{C}$ ) and the aquarium should be clean to keep the fish in healthy breeding conditions.

41| Place the mating box in an incubator at $28{ }^{\circ} \mathrm{C}$ keeping the inside of the incubator dark.

PAUSE POINT Incubate the mating box under these conditions overnight.

42| Remove the mating box from the incubator early in the morning and place the box in the light at $25-28{ }^{\circ} \mathrm{C}$. Frequently check the mating box for eggs.

\footnotetext{
Figure 4 I Images of cells and zebrafish incubated with $\mathrm{HgCl}_{2}$ and mercury probe 1. (a) Fluorescence image of C2C12 cells treated with $\mathbf{1}(10 \mu \mathrm{M})$ in the absence of external $\mathrm{Hg}^{2+}$ (scale bar, $\left.50 \mu \mathrm{m}\right)$. (b) Fluorescence image of $\mathrm{C} 2 \mathrm{C} 12$ cells treated with both $\mathrm{Hg}^{2+}(10 \mu \mathrm{M})$ and $\mathbf{1}(10 \mu \mathrm{M})$ (scale bar, $\left.50 \mu \mathrm{m}\right)$. (c) Images of a 3-day-old zebrafish treated with $1(10 \mu \mathrm{M})$ in the absence of external $\mathrm{Hg}^{2+}$ (top, microscopic image; bottom, fluorescence microscopic image) (scale bar, $200 \mu \mathrm{m})$. (d) Images of a 3-day-old zebrafish treated with both $\mathrm{Hg}^{2+}(10 \mu \mathrm{M})$ and $\mathbf{1}(10 \mu \mathrm{M})$ (top, microscopic image; bottom, fluorescence microscopic image) (scale bar, $200 \mu \mathrm{m}$ ).
}
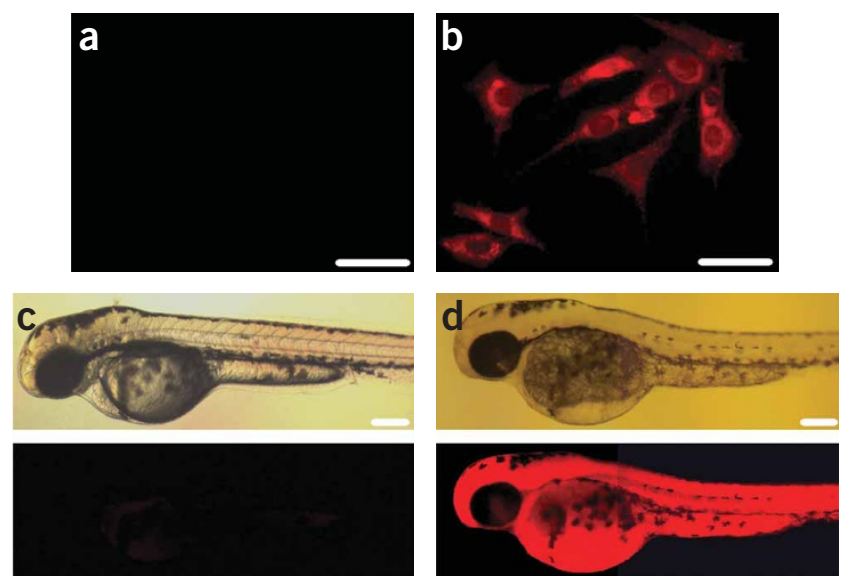
43| Once the fish spawns eggs, remove a top container and collect the embryos from the bottom container.

44| Transfer the embryos into $90 \mathrm{~mm}$ Petri dish filled with E3 media using a disposable transfer pipette.

PAUSE POINT Raise the embryos in the incubator at $28{ }^{\circ} \mathrm{C}$ for 3 days, replenishing the E3 media every day.

$\triangle$ CRITICAL STEP Dead embryos should be removed during incubation, as they induce the death of adjacent live embryos.

45 Transfer the 3-day-old zebrafish into a 96-well microplate by using a disposable transfer pipette (final volume of E3 media: $100 \mu \mathrm{l}$ ) and add $0.1 \mu \mathrm{l}$ of $10 \mathrm{mM}$ mercury chloride (final concentration: $10 \mu \mathrm{M}$ ) dissolved in E3 media.

46 Incubate the fish for $10 \mathrm{~min}$ at $28{ }^{\circ} \mathrm{C}$, remove the media solution and wash the fish three times with $100 \mu \mathrm{l}$ of E3 media to remove the remaining mercury ions.

47| Add $100 \mu$ l of E3 media to the mercury-exposed zebrafish and treat the fish with $0.1 \mu \mathrm{l}$ of $10 \mathrm{mM}$ mercury probe 1 (final concentration: $10 \mu \mathrm{M}$ ) dissolved in DMSO and incubate for $30 \mathrm{~min}$ at $37^{\circ} \mathrm{C}$.

48| Obtain images (Fig. 4d) by using a Nikon TE2000 fluorescence microscope. There is no need to remove the remaining mercury probe $\mathbf{1}$ from the media since it is not fluorescent.

\section{TIMING}

Steps 1-4: 7 h; Steps 5-8: 1 h; Steps 9-13: 4 h; Steps 14-17: 7 h; Steps 18-21: 1 h; Steps 22-26: 4 h; Step 27: 1 day; Steps 28 and 29: 1-3 days; Steps 30-34: 30 min; Step 35: 1 day; Steps 36-39: 1.5 h; Steps 40-44: 3 days and 14 h; Steps 45-48: 1.5 h

\section{ANTICIPATED RESULTS}

Typical yields

The typical isolated yield of 2 (Steps 1-13) is 90\% and the typical isolated yield of mercury probe 1 from 2 (Steps 14-26) is $90 \%$. Typical overall yield of mercury probe 1 from rhodamine $6 \mathrm{G}$ (Steps $1-26$ ) is $80 \%$.

\section{Analytical data \\ 2-(6-ethylamino-3-ethylimino-2,7-dimethyl-3H-xanthen-9-yl)benzoic acid hydrazide (2)}

White solid, mp 280-282 ${ }^{\circ} \mathrm{C}$; TLC (dichloromethane/methanol 10:1 vol/vol) $R_{\mathrm{f}}=0.51 ;{ }^{1} \mathrm{H} \mathrm{NMR}\left(\mathrm{CDCl}_{3}, 250 \mathrm{MHz}\right) \delta 7.96-7.93(\mathrm{~m}$, $1 \mathrm{H}), 7.45-7.42(\mathrm{~m}, 2 \mathrm{H}), 7.07-7.05(\mathrm{~m}, 1 \mathrm{H}), 6.39(\mathrm{~s}, 2 \mathrm{H}), 6.23(\mathrm{~s}, 2 \mathrm{H}), 3.58-3.55(\mathrm{~m}, 4 \mathrm{H}), 3.21(\mathrm{q}, \mathrm{J}=7.3 \mathrm{~Hz}, 4 \mathrm{H}), 1.91(\mathrm{~s}, 6 \mathrm{H})$, $1.31(\mathrm{t}, \mathrm{J}=7.1 \mathrm{~Hz}, 6 \mathrm{H}) ;{ }^{13} \mathrm{C}$ NMR $\left(62.9 \mathrm{MHz}, \mathrm{CDCl}_{3}\right) \delta 166.2,152.3,151.8,147.6,132.6,129.9,128.1,127.7,123.8,123.0,118.0$, 104.9, 96.9, 66.1, 38.4, 16.7, 14.8; IR (film, $\mathrm{cm}^{-1}$ ) 3,422, 2,969, 2,926, 2,864, 1,692, 1,621, 1,517, 1,468, 1,421, 1,347, 1,270, $1,216,1,157,1,011$; ESI-MS $m / z$ calculated for $\mathrm{C}_{26} \mathrm{H}_{29} \mathrm{~N}_{4} \mathrm{O}_{2}[\mathrm{M}+\mathrm{H}]^{+} 429.22$, found 429.22 .

\section{2-(6-ethylamino-3-ethylimino-2,7-dimethyl-3H-xanthen-9-yl) benzoic acid phenyl thiourea (1)}

White solid, mp 150-152 ${ }^{\circ} \mathrm{C}$; TLC (hexane/Et0Ac $\left.1: 1 \mathrm{vol} / \mathrm{vol}\right) R_{\mathrm{f}}=0.5 ;{ }^{1} \mathrm{H}$ NMR $\left(\mathrm{CDCl}_{3}, 250 \mathrm{MHz}\right) \delta 8.06-8.03(\mathrm{~m}, 1 \mathrm{H}), 7.66-7.57$ $(\mathrm{m}, 3 \mathrm{H}), 7.26-7.22(\mathrm{~m}, 3 \mathrm{H}), 3.26-3.17(\mathrm{~m}, 4 \mathrm{H}), 1.84(\mathrm{~s}, 6 \mathrm{H}), 1.32(\mathrm{t}, \mathrm{J}=7.1 \mathrm{~Hz}, 6 \mathrm{H}) ;{ }^{13} \mathrm{C} \mathrm{NMR}\left(62.9 \mathrm{MHz}, \mathrm{CDCl}_{3}\right) \delta 182.2,166.9$, $152.5,150.8,148.4,138.1,134.1,129.5,129.0,128.2,128.1,125.8,125.2,124.4,123.2,118.9,104.4,95.9,67.0,37.9,16.1$, 13.7; IR (film, cm ${ }^{-1}$ ) 3,326, 2,964, 2,960, 2,950, 2,356, 2,351, 1,713, 1,620, 1,517, 1,430, 1,424, 1,347, 1,274, 1,212, 1,089, 1,016; HRMS (FAB) $m / z$ calculated for $\mathrm{C}_{33} \mathrm{H}_{33} \mathrm{~N}_{5} \mathrm{O}_{2} \mathrm{~S}[\mathrm{M}+\mathrm{H}]^{+} 564.2423$, found 564.2433.

Probe 1 shows no fluorescence property and its absorbance maximum is at $538 \mathrm{~nm}$.

\section{Detection of mercury ions in cells and zebrafish}

The mercury probe 1 can be used to monitor mercury ions in various cells including mammalian cell lines, differentiated cells and primary cells, and in vertebrate organisms by using fluorescent imaging assays. Data on the in vivo detection of mercury are given in Figure 4. Figure $\mathbf{4 b}$ demonstrates that intracellular mercury ions in murine $\mathrm{C} 2 \mathrm{C} 12$ myoblasts can be detected by incubating the cells with mercury ion $(10 \mu \mathrm{M})$ and then with the mercury probe $\mathbf{1}(10 \mu \mathrm{M})$. More interesting (Fig. $\mathbf{4 d})$ is the fact that mercury ions in zebrafish can also be readily detected by employing this probe.

ACKNOWLEDGMENTS This work was supported by the SRC programs (R11-2000-070 and R11-2003-019) and the NRL program of MOST/KOSEF. Y.-K.Y. and S.-K.K. thank the BK21 program (KRF).

COMPETING INTERESTS STATEMENT The authors declare no competing financial interests.

Published online at http://www.natureprotocols.com

Reprints and permissions information is available online at http://npg.nature.com/ reprintsandpermissions
1. Gutknecht, J. Inorganic mercury $\left(\mathrm{Hg}^{2+}\right)$ transport through lipid bilayer membranes. J. Membr. Biol. 61, 61-66 (1981).

2. Clarkson, T.W., Magos, L. \& Myers, G.J. The toxicology of mercury-current exposures and clinical manifestations. N. Engl. J. Med. 349, 1731-1737 (2003).

3. Yoon, S., Albers, A.E., Wong, A.P. \& Chang, C.J. Screening mercury levels in fish with a selective fluorescent chemosensor. J. Am. Chem. Soc. 127, 16030-16031 (2005).

4. Valeur, B. Molecular Fluorescence: Principles and Applications (Wiley-VCH, Weinheim, 2002). 
5. Haugland, R.P. (ed.) The Handbook-A Guide to Fluorescent Probes and Labeling Technologies 10th edn. (Molecular Probes, Eugene, OR, 2005).

6. de Silva, A.P. et al. Signaling recognition events with fluorescent sensors and switches. Chem. Rev. 97, 1515-1566 (1997).

7. Fabbrizzi, L. \& Poggi, A. Sensors and switches from supramolecular chemistry. Chem. Soc. Rev. 24, 197-202 (1995).

8. Czarnik, A.W. Chemical communication in water using fluorescent chemosensors. Acc. Chem. Res. 27, 302-308 (1994).

9. Zhu, X.J., Fu, S.T., Wong, W.K., Guo, J.P. \& Wong, W.Y. A near-infrared-fluorescent chemodosimeter for mercuric ion based on an expanded porphyrin. Angew. Chem. Int. Ed. 45, 3150-3154 (2006).

10. Zheng, H., Qian, Z.H., Xu, L., Yuan, F.F., Lan, L.D. \& Xu, J.G. Switching the recognition preference of rhodamine $B$ spirolactam by replacing one atom: design of rhodamine $B$ thiohydrazide for recognition of $\mathrm{Hg}$ (II) in aqueous solution. Org. Lett. 8, 859-861 (2006).
11. Song, K.C. et al. Fluorogenic $\mathrm{Hg}^{2+}$-selective chemodosimeter derived from 8-hydroxyquinoline. Org. Lett. 8, 3413-3416 (2006).

12. Yang, Y.K., Yook, K.J. \& Tae, J. A rhodamine-based fluorescent and colorimetric chemodosimeter for the rapid detection of $\mathrm{Hg}^{2+}$ ions in aqueous media. J. Am. Chem. Soc. 127, 16760-16761 (2005).

13. Ko, S.K., Yang, Y.K., Tae, J. \& Shin, I. In vivo monitoring of mercury ions using a rhodamine-based molecular probe. J. Am. Chem. Soc. 128, 14150-14155 (2006).

14. Chae, M.Y. \& Czarnik, A.W. Fluorimetric chemodosimetry. Mercury(II) and silver(II) indication in water via enhanced fluorescence signaling. J. Am. Chem. Soc. 114, 9704-9705 (1992).

15. Yang, X.F., Guo, X.Q. \& Zhao, Y.B. Development of a novel rhodamine-type fluorescent probe to determine peroxynitrite. Talanta 57, 883-890 (2002).

16. Nusslein-Volhard, C. \& Dahm, R. Zebrafish. A Practical Approach (Oxford University Press, 0xford, UK, 2002). 


\section{Corrigendum: Synthesis of a highly metal-selective rhodamine-based probe and its use for the in vivo monitoring of mercury}

Young-Keun Yang, Sung-Kyun Ko, Injae Shin \& Jinsung Tae Nat. Protoc. 2, 1740-1745 (2007); doi:10.1038/nprot.2007.246; published online 5 July; corrected online 9 August 2007.

In the version of this article initially published, the structure of rhodamine $6 \mathrm{G}$ in Figure 1 was incorrect. The figure has been replaced in the HTML and PDF versions of the article.
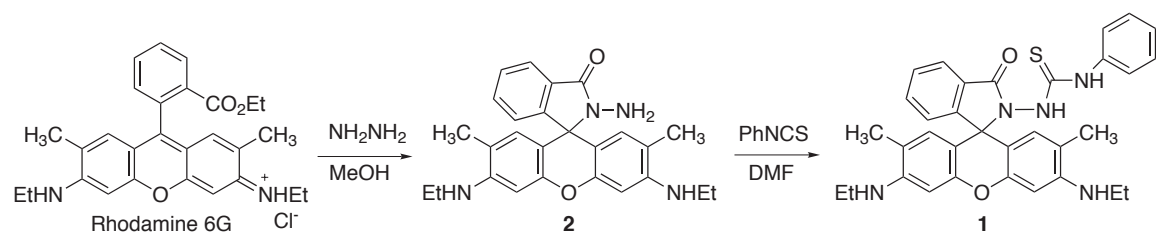